\title{
Removal of Stabilized Silver Nanoparticles from Surface Water by Conventional Treatment Processes
}

\author{
Hafiz H. M. Salih1, Amro M. El Badawy², Thabet M. Tolaymat ${ }^{3}$, Craig L. Patterson ${ }^{3 *}$ \\ ${ }^{1}$ Illinois State Geological Survey, University of Illinois, Champaign, Illinois, USA \\ ${ }^{2}$ Civil and Environmental Engineering Department at California Polytechnic State University (Cal Poly), San Luis Obispo, \\ California, USA \\ ${ }^{3}$ US Environmental Protection Agency, National Risk Management Research Laboratory, Cincinnati, Ohio, USA \\ Email: *Patterson.Craig@epa.gov
}

How to cite this paper: Salih, H.H.M., El Badawy, A.M.E., Tolaymat, T.M. and Patterson, C.L. (2019) Removal of Stabilized Silver Nanoparticles from Surface Water by Conventional Treatment Processes. $A d$ vances in Nanoparticles, 8, 21-35. https://doi.org/10.4236/anp.2019.82002

Received: April 20, 2019

Accepted: May 24, 2019

Published: May 27, 2019

Copyright (c) 2019 by author(s) and Scientific Research Publishing Inc. This work is licensed under the Creative Commons Attribution International License (CC BY 4.0).

http://creativecommons.org/licenses/by/4.0/

\begin{abstract}
Engineered nanomaterials are used in many applications, including pollution sensors, photovoltaics, medical imaging, drug delivery and environmental remediation. Due to their numerous applications, silver nanoparticles (Ag NPs) are receiving a large amount of attention. Ag NPs may occur in drinking water sources either during manufacturing, consumption and/or disposal processes. This potentially leads to the presence of Ag NPs in finished drinking water, which could have public health impacts. The objective of this research was to investigate the removal of several types of stabilized Ag NPs by potable water treatment processes. Specifically, this research achieved these objectives through: 1) Synthesis of Citrate-reduced Ag NPs, Polyvinylpyrrolidone stabilized (PVP) Ag NPs and Branched polyethyleneimine stabilized (BPEI) Ag NPs, 2) Characterization of synthesized Ag NPs to determine their aggregation potential, Zeta potential profiles, (pHpzc) and obtain morphological data from SEM images, and 3) An evaluation of the efficacy of conventional water treatment processes (i.e., coagulation, flocculation, sedimentation and sand filtration) in removing stabilized Ag NPs from natural water. The three NPs were found to be stable at the nano size in natural water. Alum coagulation had no impact on the PVP and BPEI Ag NPs. Flocculation and settling were found to be key steps for removal of these NPs. The three Ag NPs were not permanently removed by means of conventional water treatment processes employed in this study.
\end{abstract}

\section{Keywords}

Silver, Nanoparticles, Drinking Water, Water Treatment, Ag Nano Particle 


\section{Introduction}

Nanoparticles (NPs) are emerging as a new type of contaminant in water and wastewater. Synthesized NM is being used in over 1000 products, including food/beverage, sport merchandise, tires, stain resistant clothing, cosmetics, electronics, household tools and in medicine [1]. This high production and use of NPs will likely to result in the release of NPs into the environment and consequently to natural water [2] [3]. However, the fate and transport of NPs in the environment has yet to be fully understood.

Due to their numerous applications, silver nanoparticles (Ag NPs) are receiving a large amount of attention. One of the most attractive characteristics of $\mathrm{Ag}$ NPs is their antibacterial property [4]. This characteristic prompts the use of Ag NPs in many consumer products such as cosmetics, fabrics, and air and water filters, in addition to their use in medical equipment and textiles [5] [6]. Due to their extensive use, Ag NPs may occur in drinking water sources either during manufacturing, consumption and/or disposal processes. This potentially leads to the presence of Ag NPs in finished drinking water, which could have public health impacts. The actual concentrations of the engineered NPs in natural waters are unknown. However, $100 \mu \mathrm{g} / \mathrm{L}$ total NP concentrations were predicted by simple box models [7]. Once released into the environment they may be considered an emerging contaminant in water and wastewater [8].

Due to their very small size, NPs are very reactive with a smaller coordination number and more exposed reactive species on their external surface [9]. Only $1 \%$ of the atoms are exposed to the external environment on a microparticle [1]. This percentage is increased to $10 \%$ on particles $10 \mathrm{~nm}$ in diameter and to $60 \%$ on smaller particles with a diameter of $2 \mathrm{~nm}$. Once NPs aggregate into larger particles they may lose their unique surface properties and behave like normal colloids. Stable NPs that resist aggregation are very desirable in many fields including water and wastewater treatment. Hence, the unique and desirable characteristics of Ag NPs, including their toxicity, are mainly due to their small size. This gave rise to vast research efforts to produce Ag NPs resistant to aggregation and that stay at the nano-size for a long time [10]. This research has expedited the emergence of new synthetically-engineered Ag NPs. However, the behavior of these engineered NPs and their fate and transport in water is yet to be determined. Further, their induced stability makes their removal from drinking water more difficult. A large percentage of the available synthesis methods are capable of producing stable Ag NPs with a minimal likelihood of agglomeration [10]. This implies that the possibility for the mobility of Ag NPs in the environment may be higher than previously assumed [11]. The stability of Ag NPs is a function of many factors including the type of capping agent, the surrounding environmental conditions (e.g., $\mathrm{pH}$ and ionic strength), and the background electrolyte composition. Capping agents are chemicals (such as polymers and surfactants) used in the synthesis of Ag NPs to prevent their aggregation through electrostatic repulsion, steric repulsion, or both. Ag NPs are synthesized using many 
techniques that result in various shapes and sizes. The most frequently used techniques involve the dissolution of a silver salt in a solvent and the subsequent addition of a reducing agent [12]. NPs have a high tendency to form aggregates, this is due to their high specific surface area to volume ratio that gives rise to high reactivity which forces NPs to aggregate [2] [11]. This physical phenomenon is hindered by introducing stabilizing agents (capping agents). Capping agents prevent the agglomeration of the NPs by increasing their surface charge (electrostatic), steric stabilization (electro steric) or a combination of both [13].

Natural organic matter (NOM) is the product of the breakdown of dead plants and animals. NOM exists in many types of drinking water sources at the mg/L level [14]. NOM has a substantial influence on NP stability in water [15]. Many researchers have reported that the presence of dissolved NOM increases the negative charge on the surface of the NPs [16] [17] [18]. Chen and Elimelech reported that the presence of humic acid (HA) gave rise to steric repulsion among fullerene $C_{60}$ NPs [19]. They concluded that this steric repulsion effectively stabilized the NPs in suspension. HA or fulvic acid (FA) are often used to represent NOM because they are responsible for most of the reactivity of NOM [20] [21].

Information in the literature is limited regarding the removal of stabilized $\mathrm{Ag}$ NPs by conventional water treatment processes. In this study, three types of stabilized Ag NPs with different surface properties were synthesized. Characterization and aggregation studies were conducted on three Ag NPs to confirm their stability in natural water. The Ag NPs were then subjected to potable water treatment methods to investigate their removability. This study increases the understanding of NP fate and transport in potable water. This knowledge is vital due to the potential health risks imposed by NPs. Results from this study will enable better prediction of the fate and transport of these materials. Accordingly, engineered systems could be designed for their removal from contaminated sites or at least minimize their hazard by enhancing their coagulation so they became less bioavailable.

\section{Materials and Methods}

\subsection{Water}

All Ag NP (Sigma-Aldrich, Milwaukee, WI) suspensions were prepared in Super-Q water with a resistivity greater than 18.3 megaohms-centimeter $(\mathrm{M} \Omega-\mathrm{cm})$ to obtain SEM images, zeta size analysis, and to study the effect of alum on the Ag NPs. The Ag NP suspensions were prepared in raw Ohio River water obtained from the pumping station of the Greater Cincinnati Water Works in Cincinnati, Ohio to study Ag NP stability in natural water and their removal by drinking water treatment methods.

\subsection{Synthesis and Preparation of the Ag NP Suspensions}

The following methods were selected to prepare and synthesize stabilized Ag 
NPs. These methods were chosen because they are commonly used to produce stable Ag NPs. The resultant NPs were purified using a KrosFlo ${ }^{\circledR}$ Research IIi TFF system (Spectrum Labs) to remove silver ions.

\subsubsection{Citrate Reduced Ag NPs}

Citrate reduced $\mathrm{Ag}$ NPs were produced utilizing a solution of $0.001 \mathrm{M} \mathrm{AgNO}_{3}$ mixed with a solution of $0.1 \mathrm{M} \mathrm{Na}_{3} \mathrm{C}_{6} \mathrm{H}_{5} \mathrm{O}_{7} \cdot 2 \mathrm{H}_{2} \mathrm{O}$ in a volume ratio of 2:1 [12]. The mixture was heated at $70^{\circ} \mathrm{C}$ for 4 hours in a water bath.

\subsubsection{Polyvinylpyrrolidone Stabilized (PVP) Ag NPs}

The PVP-AgNPs were synthesized by adding a $50 \mathrm{~mL}$ solution of $5 \mathrm{mM} \mathrm{AgNO}_{3}$ ( 1 drop per second) to vigorously stirred ice-cold $0.002 \mathrm{M} \mathrm{NaBH}_{4}$ dissolved in $1 \%$ PVP solution at a final volume ratio of 1:3, respectively [22].

\subsubsection{Branched Polyethyleneimine Stabilized (BPEI) Ag NPs}

BPEI Ag NPs were synthesized by separately dissolving branched polyethyleneimine (BPEI) $\left(99 \%, \mathrm{M}_{\mathrm{w}}=1.20 \mathrm{~kg} \cdot \mathrm{mol}^{-1}\right)$ and $\mathrm{AgNO}_{3}$ in a $1 \times 10^{-4} \mathrm{M}$ solution of $\mathrm{N}$-(2-hydroxyethyl) piperazine-N'-2-ethanesulfonic acid (HEPES) [23]. The two solutions were mixed in a volume ratio of 1:1 to give a final molar ratio of 0.5:1:0.1 BPEI:AgNO ${ }_{3}: \mathrm{HEPES}$, respectively. After mixing, the solution was exposed for 2 hours to UV irradiation using a standard low-pressure mercury arc lamp.

\subsection{Analytical Methods}

The hydrodynamic diameters (HDD) of the three Ag NPs were determined by dynamic light scattering (DLS) using a Zetasizer Nanoseries (Malvern Instruments, Westborough, MA) with a $633 \mathrm{~nm}$ laser source and a detection angle of $173^{\circ}$ (detection range $1 \mathrm{~nm}$ to $10 \mu \mathrm{m}$ ). The same instrument was used to measure the electrophoretic mobility which was subsequently transformed to $\zeta$ potential using Smoluchowski's approximation. Scanning electron microscopy (SEM) was used to verify the characteristics (size and shape) of the NPs. The elemental composition of the dried Ag NP suspensions was obtained using an Energy FEI/Philips XL30 FEG scanning electron microscope with EDAX software and Electron Backscatter Diffraction (EBSD) analytical capability. This was performed to study the interaction between the Ag NPs and the natural water colloids.

Microwave acid digestion using $70 \%$ nitric acid $\left(\mathrm{HNO}_{3}\right)$ as described in EPA method 3051 A [24] followed by Inductively Coupled Plasma (ICP-optical emission) analysis was used to quantify the sensitized Ag NP concentrations in the stock suspensions. The chemical content of the raw water was assessed by ICP, TOC VCPN (Shimadzu Corp., Japan). The total solid content was obtained by drying three samples at $103^{\circ} \mathrm{C}-105^{\circ} \mathrm{C}$ for 24 hours.

The UV absorbance of the Ag NP suspensions was measured using a dual beam UV-Vis spectrophotometer (UV-1650PC, Shimadzu Scientific Instruments) to measure the $\mathrm{Ag} \mathrm{NP}$ concentrations in natural water before and after 
treatment. UV-Vis absorbance by Ag NPs can be used as an indicator of their size and concentration. The larger the particle, the more shift to a longer wavelength for the spectrum peak. This also usually co-occurs with a decrease in peak height. Ag NPs can be quantified also assuming that there is no change in aggregation. This results in spectra where the peak stays at the same wavelength but decreases as a function of decreasing concentration. The change of the absorbance peaks was interpreted as Ag NP aggregation and thus removal.

\subsection{Ag NP Characterization}

All Ag NP characterization and removal studies were performed at Ag NP concentrations of $5.0 \mathrm{mg} / \mathrm{L}$. The aggregation potential of the three Ag NPs in natural water was obtained by placing the Ag NP dispersions in natural water and taking zeta-sizer cuvette readings automatically obtained every minute for 30 minutes. The impact of the alum addition was measured by adding alum doses of 15, 30, 45 and $60 \mathrm{mg} / \mathrm{L}$ to the Ag NP suspensions in deionized (DI) water. The HDD of the three Ag NPs was then monitored for 30 minutes using the zeta-sizer.

\subsection{Removal of the Ag NPs during Drinking Water Treatment}

In this section of the research, the investigators explored the efficacy of water treatment processes (i.e., coagulation, flocculation, sedimentation, sand filtration and direct sand filtration) in removing stable Ag NPs from raw water obtained from the Ohio River. Alum $\mathrm{Al}_{2}\left(\mathrm{SO}_{4}\right)_{3}$ at a concentration of $20 \mathrm{mg} / \mathrm{L}$ (optimal dose for the natural water used in this study) was added as a coagulant. The Ag NP suspensions were then studied during four stages of drinking water treatment (coagulation, flocculation, sedimentation and sand filtration). The first stage was rapid mixing at $100 \mathrm{rpm}$ for $1 \mathrm{~min}$, the second stage was slow mixing at $30 \mathrm{rpm}$ for $30 \mathrm{~min}$, and the third stage was settling for one hr. The supernatant water was then passed through a sand column in the fourth stage. All Ag NPs suspensions were treated by conventional treatment and direct filtration as follows:

1) Conventional Treatment: The Ag NP suspensions were treated using coagulation, flocculation, settling and sand filtration.

2) Direct filtration with flocculation: The Ag NP suspensions were treated by coagulation, flocculation and sand filtration with no settling step.

3) Direct filtration with no flocculation: The Ag NP suspensions were treated by coagulation and sand filtration with no settling or flocculation steps.

A Phipps \& Bird (Richmond, VA) Column Filtration System ${ }^{\text {tm }}$ (CFS) was used to simulate the water treatment process of direct filtration at a water treatment plant. The device is the traditional Phipps \& Bird Jar Tester Stirrer with 2-liter molded square acrylic flocculation jars connected to a Phipps \& Bird Column Filtration System. The column design parameters were chosen to mimic the sand filters at the Greater Cincinnati Water Works as shown in Table 1. 
Table 1. Comparison of GCWW and study sand filter specifications.

\begin{tabular}{ccc}
\hline Parameter & $\begin{array}{c}\text { Greater Cincinnati Water } \\
\text { Works Sand Filter }\end{array}$ & Study Sand Filter \\
\hline Depth & $61 \mathrm{~cm}$ & $10 \mathrm{~cm}$ \\
Area & $438.9 \mathrm{~m}^{2}$ & $36.5 \mathrm{~cm}^{2}$ \\
EBCT & $5-6 \mathrm{~min}$ & $5.6 \mathrm{~min}$ \\
Flow rate & $3 \mathrm{~g} / \mathrm{ft}^{2} / \mathrm{min}$ & $1.5 \mathrm{ml} / \mathrm{min}$ \\
Sand size & $0.45-0.55 \mathrm{~mm}$ & $0.45-0.55 \mathrm{~mm}$ \\
\hline
\end{tabular}

\section{Results and Discussions}

\subsection{Ag NP Characterization}

The methods used to synthesize the three Ag NPs yielded stabilized Ag NPs with a HDD of $10 \mathrm{~nm}$ for the citrate and BPEI Ag NPs and $12 \mathrm{~nm}$ for the PVP Ag NPs. SEM images and physical characterizations are given elsewhere [12] [25]. NPs have a high tendency to form aggregates. This is due to their high specific surface area to volume ratio that gives rise to high surface energy which forces NPs to aggregate [2]. This physical phenomenon was hindered in the case of the Ag NPs under investigation. The stability of Ag NPs was attributed to the presence of a capping (stabilizing) agent. Capping agents are used in the synthesis process to prevent the nanoparticles from aggregating. Charge stabilization is attributed to the adsorption of counter ions on the colloidal particle surface (such as $\mathrm{BH}^{4-}$ ) or the protonation of specific functional groups adsorbed on the particle surface (such as the $\mathrm{COO}^{-}$in the case of citrate). Steric stabilization occurs due to the adsorption of a polymer on the particle surface. This polymer could be uncharged polymer (such as polyvinylpyrrolidone) or a polyelectrolyte (polymers whose repeating units bear an electrolyte group that dissociates in aqueous solutions, making the polymers charged). In Figure 1, the Ag NP HDDs were plotted against time. The data in Figure 1(a) clearly suggest that the NP dispersions were very stable in natural water. This was due to the repulsive forces that emerged between the Ag NPs and the natural colloids in the water being treated (suspended solids of $10 \mathrm{mg} / \mathrm{L}$ ). It is also assumed that the presence of NOM increased the surface charge of Ag NPs. The concentration of NOM in the raw water was $3.69 \mathrm{mg} / \mathrm{L}$. The presence of NOM may further stabilize NPs through steric repulsion [18] [19]. This is due to the capability of NOM to act as a polyelectrolyte in water [26] [27]. Table 2 and Figure 2 represent the Ag NP surface charges in DI and natural water with different alum concentrations. The data in Table 2 show the impact of the background material in the natural water on the Ag NP surface charge. The BPEI Ag NP surface charge was changed from +36.1 to -3.2 due to the attachment of the negatively charged background material in the natural water.

The addition of alum at different doses did not affect the surface charge of the PVP or BPEI Ag NPs. While the addition of alum noticeably impacted the surface charge and thus the HDD of the citrate coated Ag NPs. This may be due to 

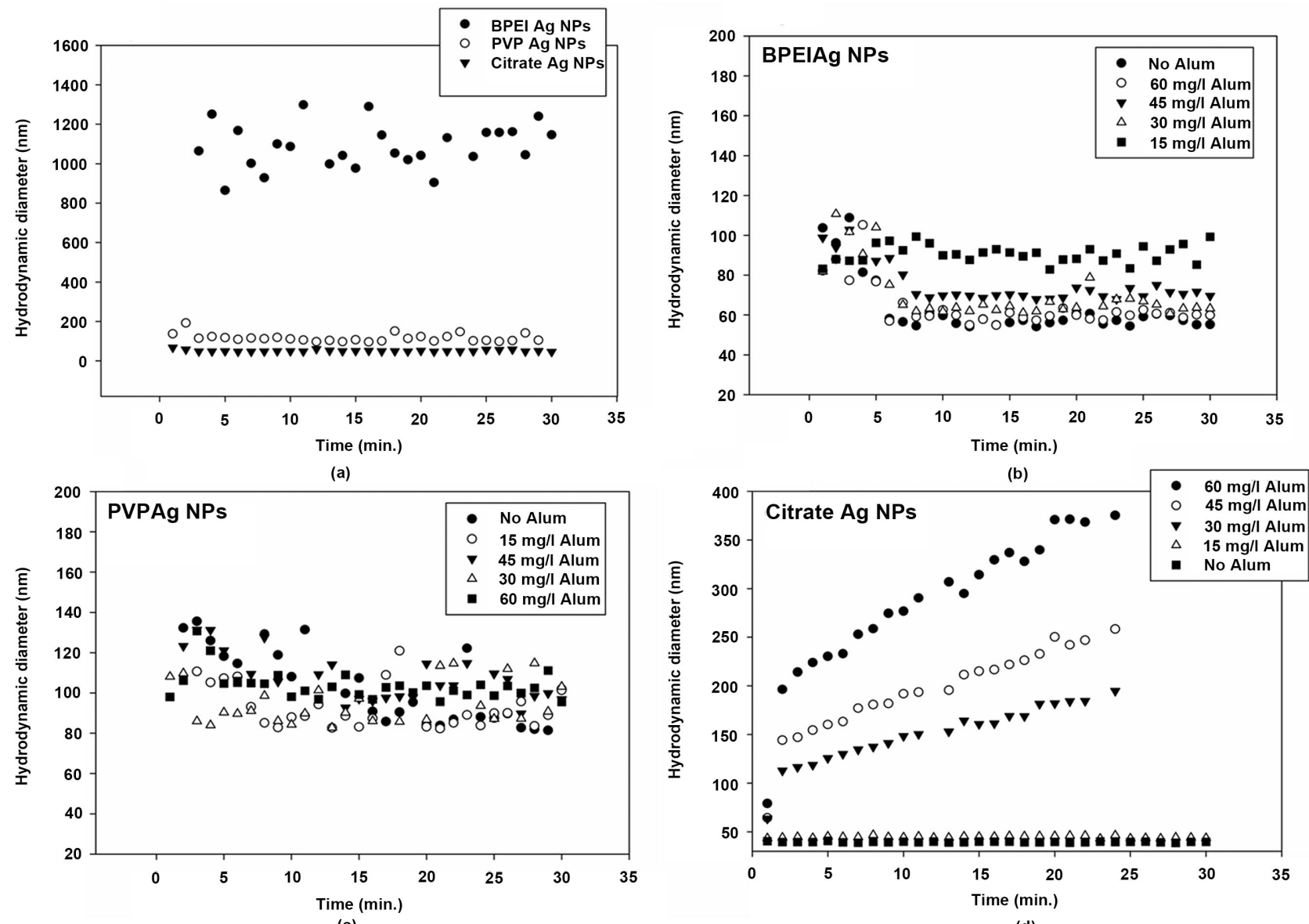

(c)

(d)

Figure 1. (a) The three Ag NPs aggregation in raw water within the absence of alum, (b) BPEI Ag NP, (c) PVP Ag NP and (d) Citrate Ag NP aggregation in DI water with alum dose ranging from 0 to $60 \mathrm{mg} / \mathrm{L}$.

Table 2. Zeta potential of Ag NPs in raw and deionized water with various Alum doses.

\begin{tabular}{ccccccc}
\hline & $\begin{array}{c}\text { No Alum in } \\
\text { Raw Water }\end{array}$ & $\begin{array}{c}\text { No Alum in } \\
\text { DI Water }\end{array}$ & $\begin{array}{c}15 \mathrm{mg} / \mathrm{L} \\
\text { Alum in DI } \\
\text { water }\end{array}$ & $\begin{array}{c}\text { 30mg/L } \\
\text { Alum in DI } \\
\text { water }\end{array}$ & $\begin{array}{c}\mathbf{4 5} \mathbf{m g} / \mathrm{L} \\
\text { Alum in DI } \\
\text { water }\end{array}$ & $\begin{array}{c}\mathbf{6 0} \mathbf{m g} / \mathrm{L} \\
\text { Alum in DI } \\
\text { water }\end{array}$ \\
\hline PVP Ag & -9.2 & -2.6 & -0.8 & -0.3 & -0.15 & -1.2 \\
NPs & \pm 5.7 & \pm 11.6 & \pm 8.1 & \pm 7.1 & \pm 7.4 & \pm 8.9 \\
BPEI Ag & -3.2 & +36.1 & +9.6 & +11.6 & +10.8 & +11.9 \\
NPs & \pm 4.9 & \pm 16.6 & \pm 9.6 & \pm 7.5 & \pm 12.2 & \pm 7.9 \\
Citrate Ag & -13.6 & -36.9 & -12.1 & -10.4 & -7.2 & +5.9 \\
NPs & \pm 6.3 & \pm 6.7 & \pm 14.1 & \pm 5.7 & \pm 4.7 & \pm 1.2 \\
\hline
\end{tabular}

the ability of the sulfate ions $\mathrm{SO}_{4}^{2-}$ to replace the citrate molecule (COO-) on the surface of the Ag NPs. The PVP and BPEI Ag NPs were characterized with a high-molecular-weight that hindered replacement by the sulfate ions $\mathrm{SO}_{4}^{2-}$ as shown in Figure 1(b), Figure 1(c) and Figure 1(d) and Table 2.

\subsection{Removal of the Ag NPs during Drinking Water Treatment}

Coagulation/flocculation aggregates small particles in water into larger, heavier clusters that settle out in short time. In theory, once alum $\mathrm{Al}_{2}\left(\mathrm{SO}_{4}\right)_{3}$ is added to 


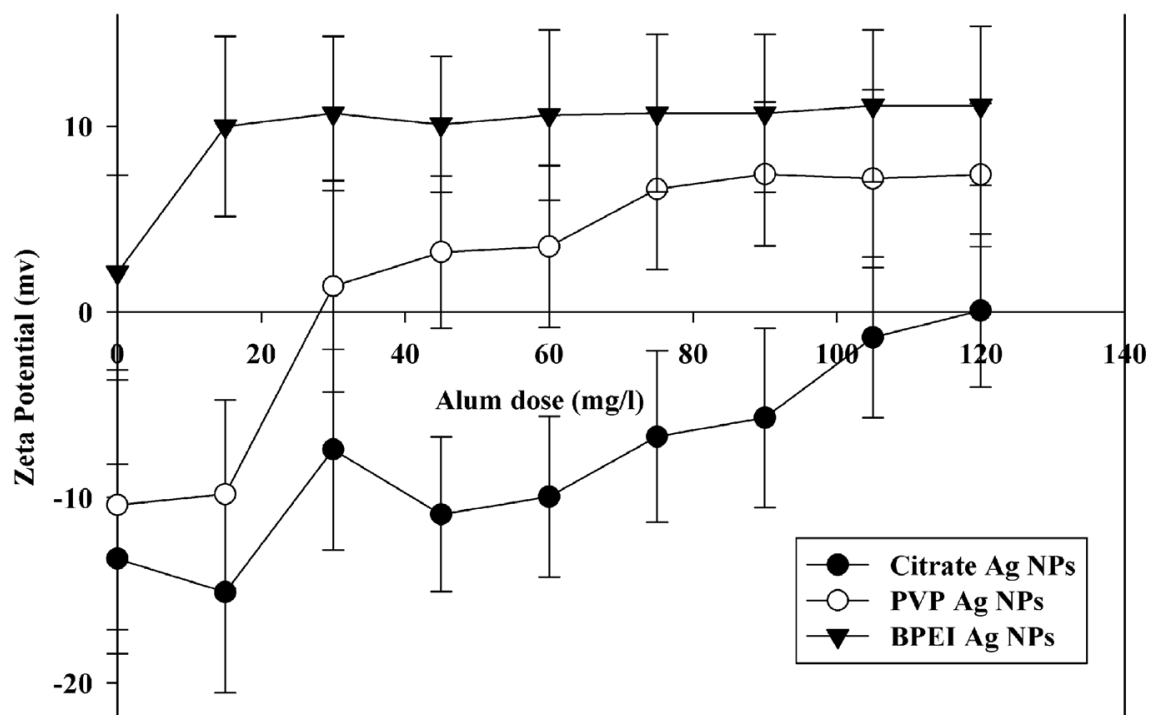

Figure 2. Ag NP zeta potential in raw water.

water, the alum will dissociate into $2 \mathrm{Al}^{3+}$ and $3 \mathrm{SO}_{4}^{2-}$-ions. Depending on the $\mathrm{pH}$ of the water, the trivalent ions of $\mathrm{Al}^{3+}$ will hydrate to give rise to a variety of mononuclear and polynuclear aluminum species. The species that emerge will interact with the suspended particles and stabilize them. The mechanism by which the alum coagulant application facilitates fine particle removal from water is explained by two theories. The first theory adopts the neutralization of the surface charge of the particles so that they can stick to each other forming larger aggregates which can settle out by gravity in a reasonable time. The second theory is the sweep flocs theory [28]. This theory simply assumes that the coagulant forms a precipitate which settles by gravity in a reasonable time. These coagulant flocs then collide with and drag fine particles down with them. Due to the resistance of the PVP and the BPEI particles to the environmental changes induced by the alum (Section 3.1), the second theory is assumed to be the mechanism through which Ag NPs are removed from natural water in this study. Figure 3 illustrates Ag NP removal in the conventional filtration setup. The Ag NP UV-Vis Absorbance peaks (concentration or aggregation) were normalized by dividing the effluent peak by the influent peak $\left(\mathrm{C} / \mathrm{C}_{\mathrm{o}}\right)$ and plotted versus time. A time of 375 minutes was set to be the breakthrough point (i.e., the point at which the column experiments were stopped). The data presented in Figure 3 shows the importance of the flocculation and settling steps in the removal of stabilized Ag NPs. More than $85 \%$ of the initial concentration of the BPEI and PVP coated Ag NPs was removed during the flocculation/settling stage. However, the concentration of the citrate coated Ag NPs was not affected by the flocculation step. Figures 4(a), Figures 4(b) and Figures $4(\mathrm{c})$ provide jar test images of the Ag NPs in alum flocs. The presence of the PVP and the BPEI on the Ag NPs lead to the formation of large flocs. These flocs were formulated by polymer bridging [29]. The polymer (PVP, BPEI) bound to the Ag NPs has coiled and dangling chains which can attach to nearby alum neutralized suspended particles. Thus, 


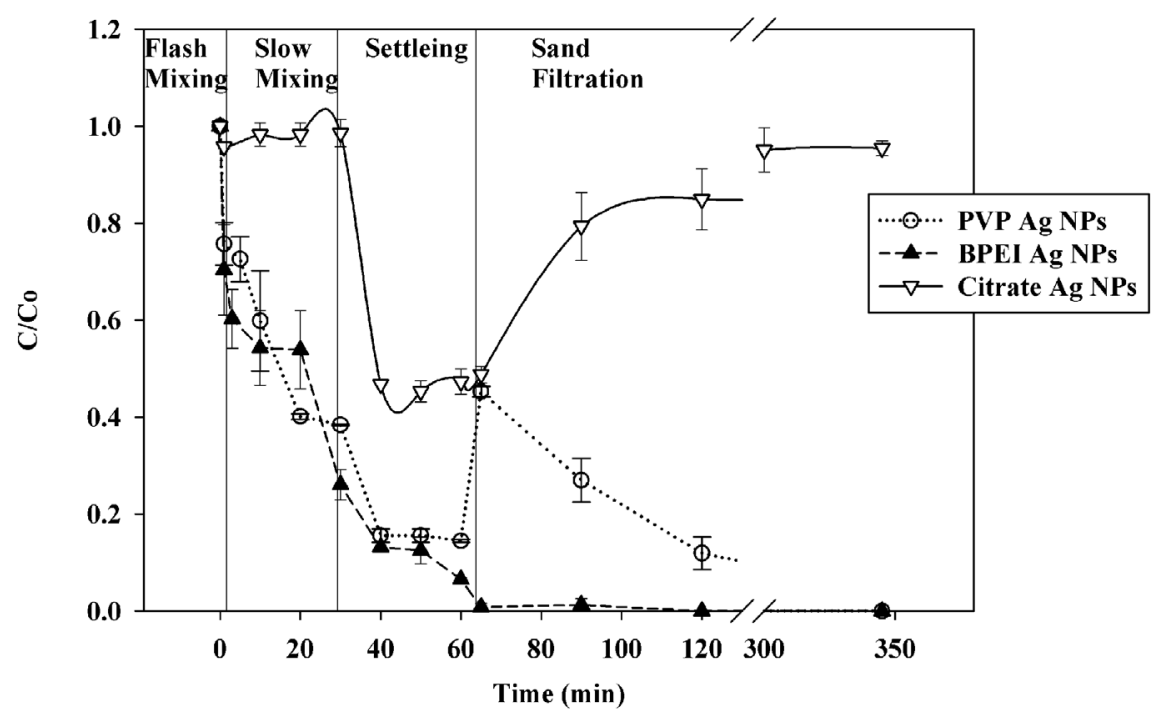

Figure 3. Ag NP removals during conventional treatment.

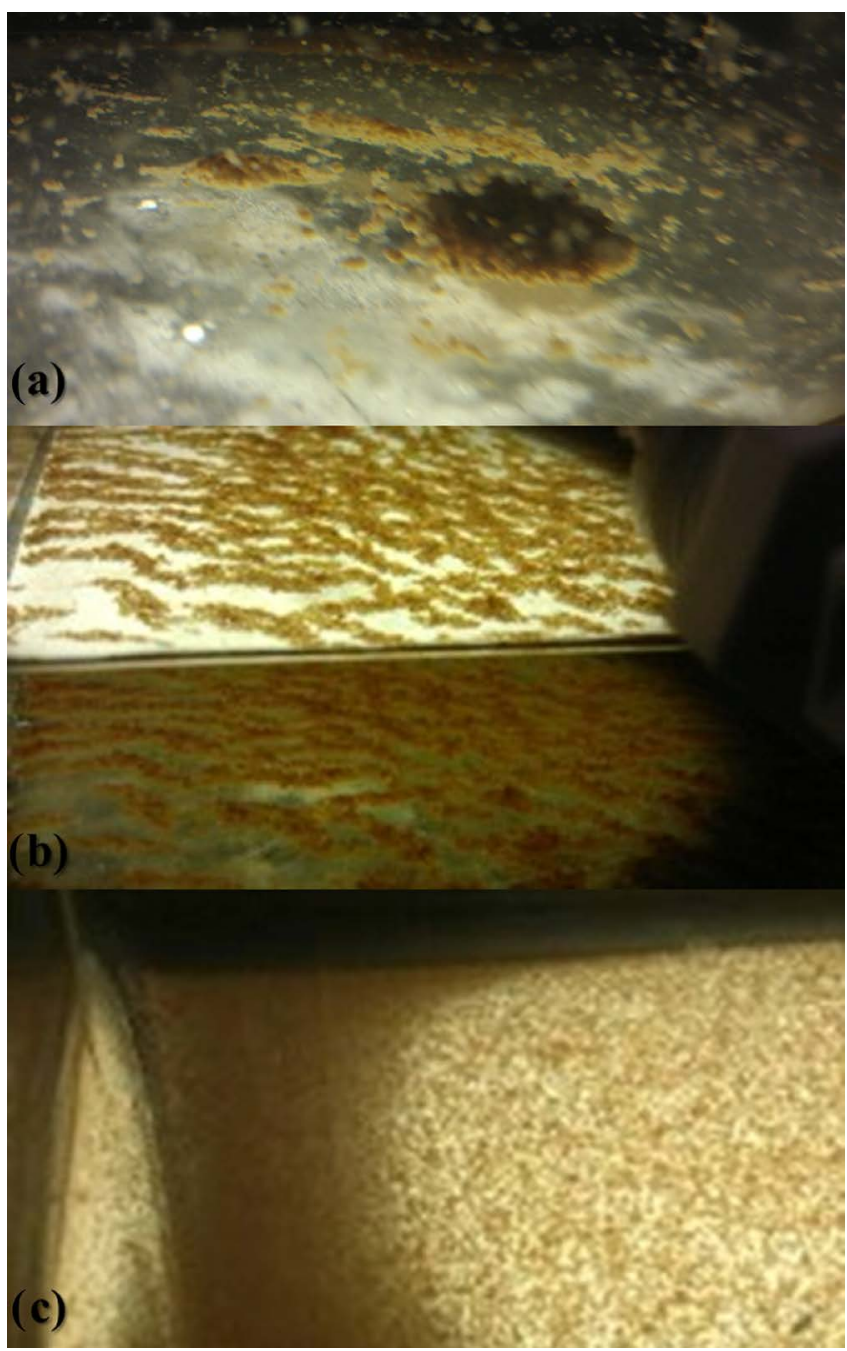

Figure 4. Photos of the (a) PVP Ag NP flocs, (b) BPEI Ag NP flocs, and (c) Citrate Ag NP flocs. 
the Ag NPs were swept out of the suspension due to their interaction with the surrounding particles. In the case of the citrate coated Ag NPs, the presence of the excess citrate hindered the floc formulation and thus reduced the sweeping mechanism (i.e., the interaction with the suspended particles in the raw water). The attachment of the Ag NPs on the larger aggregates was confirmed by obtaining their SEM images along with the EDAX software analysis. Figure 5 shows the attachment or the Ag NPs on the larger aggregates. The big particles are colloids in water and the small shiny particles are the attached Ag NPs.

The sand filtration region in Figure 3 shows that the sand filter has actually retained all the BPEI Ag NPs. This is due to their positively-charged surface. The transport and deposition of particles in a sand filter are highly impacted by the electrostatic interaction between these NPs and the filter media. Normally, sand filters are negatively charged in most water treatment processes [30]. Due to their larger flocs, the PVP Ag NP are likely retained by the filter media by physical means (see Figure 5). The retention of the PVP Ag NP-containing flocs inside the sand filter reduced the filter porosity and resulted in better Ag NP removal. On the other hand, the citrate Ag NP effluent peak is larger than the influent peak. This is due to detachment of the Ag NPs that are adsorbed on the small flocs formed during the settling time. It is worthwhile to mention that the three Ag NPs were released back into the water as nano particles by mechanical mixing in the settling tank for 30 seconds, or by increasing the flow rate of the sand filter. This shows that the Ag NPs were not permanently removed. Thus, the interaction between these NPs and the surrounding particles in natural water is readily reversible. Figure 6 and Figure 7 represent the data obtained from direct filtration with and without flocculation studies. The data in Figure 6 and Figure 7 are in agreement with the above discussion and this emphasizes the importance of the flocculation and settling steps. The floc formation delayed the BPEI breakthrough in Figure 6 when compared to the fast breakthrough in the absence of flocs in Figure 7. Also, the presence of the floc resulted in a higher efficiency in retaining the PVP Ag NPs compared to the filter performance in Figure 6. The lack of floc formation and the surface charge of the citrate Ag NPs resulted in immediate breakthrough with poor filter retention for this Ag NP.

\section{Conclusion}

In this research, three types of stabilized Ag NPs with different surface properties were synthesized. Characterization and aggregation studies were conducted on three Ag NPs to confirm their stability in natural water. The Ag NPs were then subjected to potable water treatment methods to investigate their removal efficacy. Our results suggest that the investigated Ag NPs are stable in natural water. Ag NPs interact with colloids in natural water and are removed by attaching to the aggregated colloids during settling. Unlike citrate Ag NPs, the PVP and BPEI Ag NPs are not affected by the presence of alum at any dose. Alum noticeably impacted the surface charge and HDD of Citrate-coated Ag NPs. This may have been due to the ability of the sulfate ions $\left(\mathrm{SO}_{4}^{2-}\right)$ to replace 

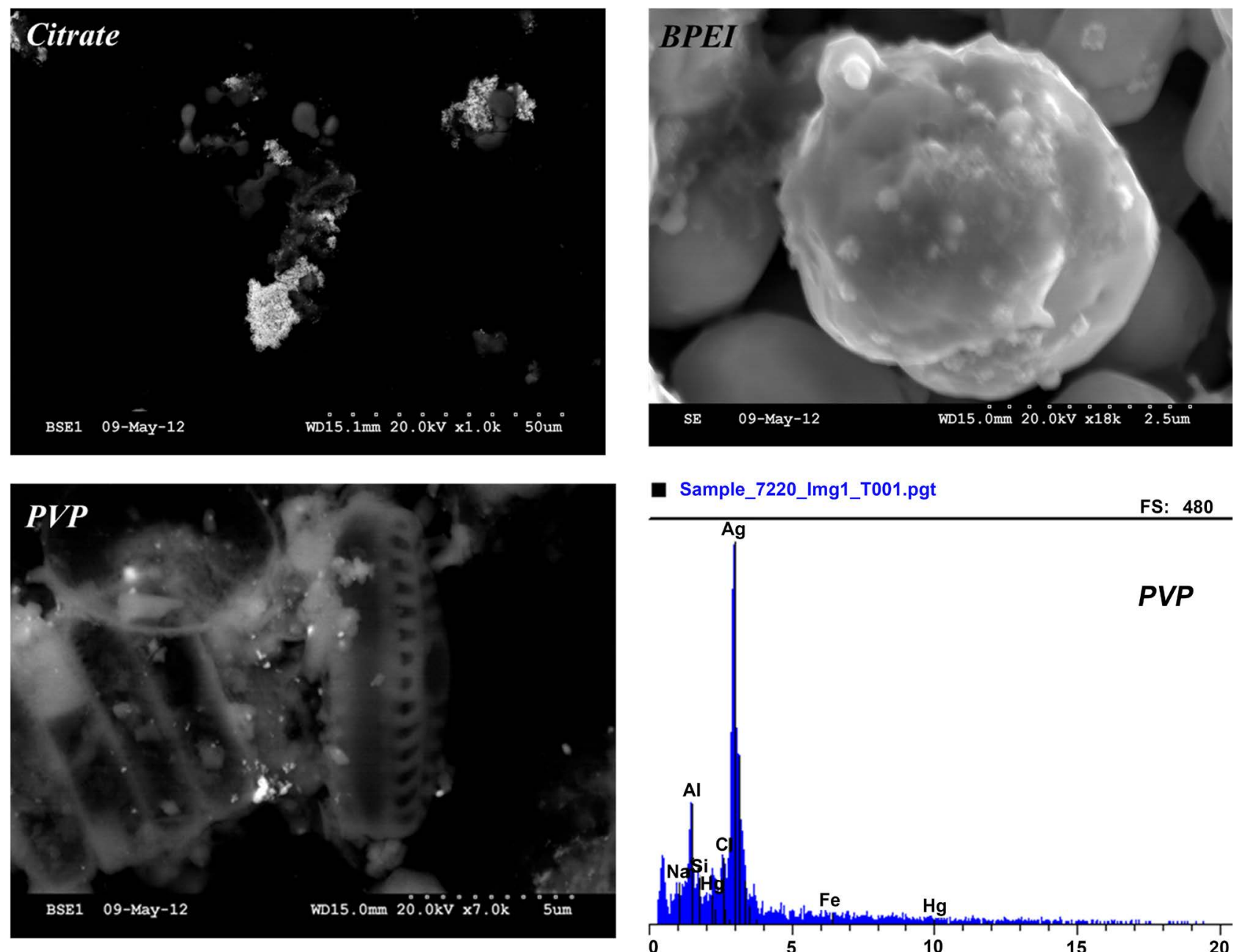

Figure 5. SEM, EDAX software analysis of Ag NPs in natural water.

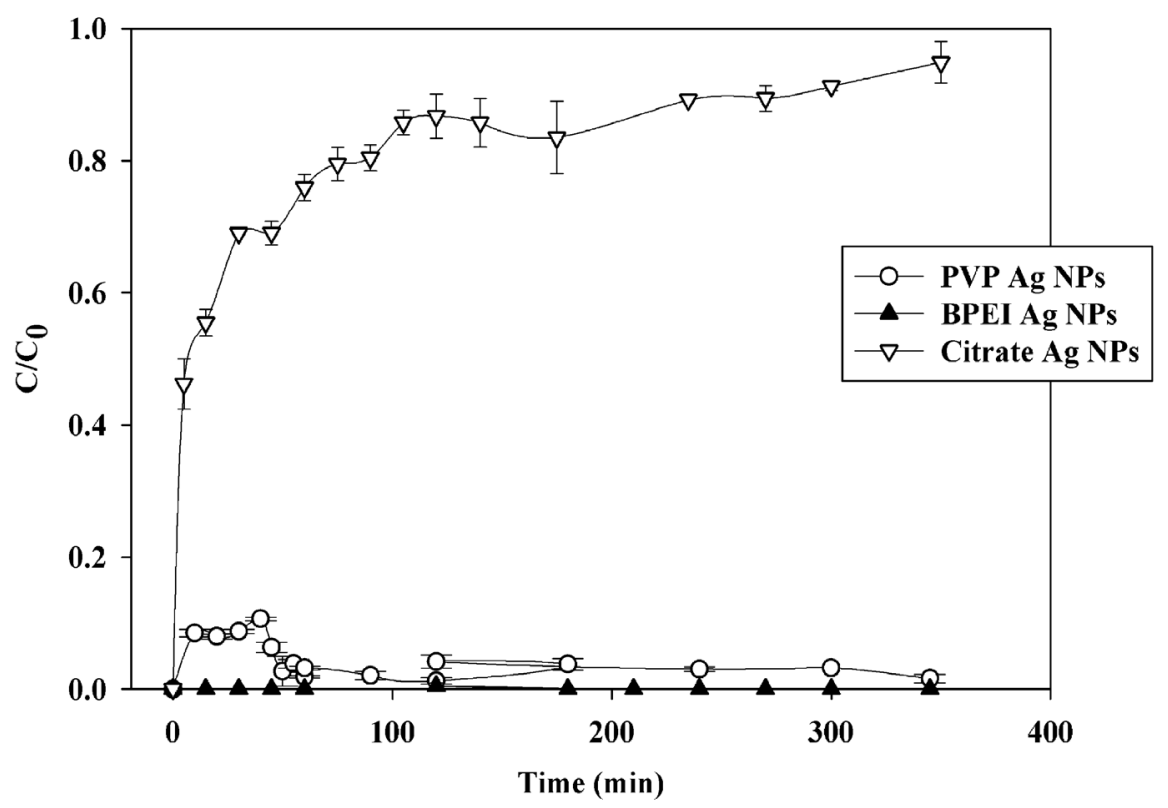

Figure 6. Ag NP removal during direct filtration with flocculation. 


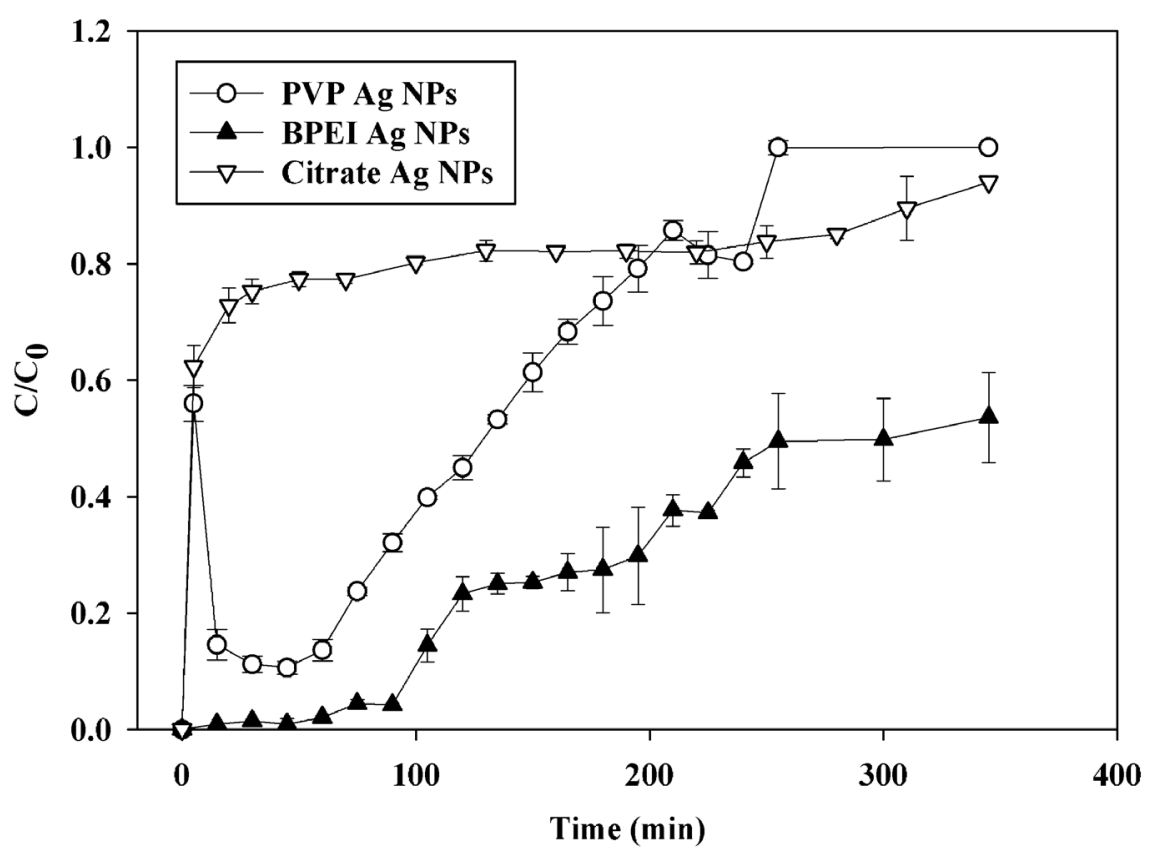

Figure 7. Ag NP removal during direct filtration without flocculation.

the citrate molecule $\left(\mathrm{COO}^{-}\right)$. PVP and BPEI Ag NPs were not permanently removed. Mechanical mixing of Ag NP aggregates for $30 \mathrm{sec}$ in the settling tank and increased flow rate in the sand filter released the Ag NPs in their original nano-size back into the test water.

\section{Disclaimer}

The US Environmental Protection Agency, through its Office of Research and Development, funded and managed, or partially funded and collaborated in, the research described herein. It has been subjected to the Agency's administrative review and has been approved for external publication. Any opinions expressed in this paper are those of the author(s) and do not necessarily reflect the views of the Agency, therefore, no official endorsement should be inferred. Any mention of trade names or commercial products does not constitute endorsement or recommendation for use.

\section{Conflicts of Interest}

The authors declare no conflicts of interest regarding the publication of this paper.

\section{References}

[1] Nel, A., Xia, T., Mädler, L. and Li, N. (2006) Toxic Potential of Materials at the Nanolevel. Science, 311, 622-627. https://doi.org/10.1126/science.1114397

[2] Ju-Nam, Y. and Lead, J.R. (2008) Manufactured Nanoparticles: An Overview of Their Chemistry, Interactions and Potential Environmental Implications. Science of the Total Environment, 400, 396-414. 
https://doi.org/10.1016/j.scitotenv.2008.06.042

[3] Klaine, S.J. (2008) Nanomaterials in the Environmental: Behavior, Fate, Bioavailability, and Effects. Environmental Toxicology, 27, 1825-1851.

https://doi.org/10.1897/08-090.1

[4] Li, Q., Mahendra, S., Lyon, D.Y., Brunet, L., Liga, M.V., Li, D. and Alvarez, P.J.J. (2008) Antimicrobial Nanomaterials for Water Disinfection and Microbial Control: Potential Applications and Implications. Water Research, 42, 4591-4602. https://doi.org/10.1016/j.watres.2008.08.015

[5] Benn, T.M. and Westerhoff, P. (2008) Nanoparticle Silver Released into Water from Commercially Available Sock Fabrics. Environmental Science \& Technology, 42, 4133-4139. https://doi.org/10.1021/es7032718

[6] Blaser, S.A., Scheringer, M., MacLeod, M. and Hungerbühler, K. (2008) Estimation of Cumulative Aquatic Exposure and Risk Due to Silver: Contribution of $\mathrm{Na}$ no-Functionalized Plastics and Textiles. Science of the Total Environment, 390, 396-409. https://doi.org/10.1016/j.scitotenv.2007.10.010

[7] Boxall, A., Chaudhry, Q., Sinclair, C., Jones, A., Aitken, R., Jefferson, B. and Watts, C. (2007) Current and Future Predicted Environmental Exposure to Engineered Nanoparticles. Central Science Laboratory, York.

[8] Park, H.-J., Kim, H.Y., Cha, S., Ahn, C.H., Roh, J., Park, S., Kim, S., Choi, K., Yi, J., Kim, Y. and Yoon, J. (2013) Removal Characteristics of Engineered Nanoparticles by Activated Sludge. Chemosphere, 92, 524-528.

https://doi.org/10.1016/j.chemosphere.2013.03.020

[9] Pan, B. and Xing, B. (2010) Manufactured Nanoparticles and Their Sorption of Organic Chemicals. In: Donald, L.S., Ed., Advances in Agronomy, Academic Press, Cambridge, 137-181. https://doi.org/10.1016/S0065-2113(10)08003-X

[10] Tolaymat, T.M., El Badawy, A.M., Genaidy, A., Scheckel, K.G., Luxton, T.P. and Suidan, M. (2010) An Evidence-Based Environmental Perspective of Manufactured Silver Nanoparticle in Syntheses and Applications: A Systematic Review and Critical Appraisal of Peer-Reviewed Scientific Papers. Science of the Total Environment, 408, 999-1006. https://doi.org/10.1016/j.scitotenv.2009.11.003

[11] Zhang, Y., Chen, Y., Westerhoff, P., Hristovski, K. and Crittenden, J.C. (2008) Stability of Commercial Metal Oxide Nanoparticles in Water. Water Research, 42, 2204-2212. https://doi.org/10.1016/j.watres.2007.11.036

[12] El Badawy, A.M., Luxton, T.P., Silva, R.G., Scheckel, K.G., Suidan, M.T. and Tolaymat, T.M. (2010) Impact of Environmental Conditions (pH, Ionic Strength, and Electrolyte Type) on the Surface Charge and Aggregation of Silver Nanoparticles Suspensions. Environmental Science \& Technology, 44, 1260-1266. https://doi.org/10.1021/es902240k

[13] Jiang, J., Oberdörster, G. and Biswas, P. (2009) Characterization of Size, Surface Charge, and Agglomeration State of Nanoparticle Dispersions for Toxicological Studies. Journal of Nanoparticle Research, 11, 77-89.

https://doi.org/10.1007/s11051-008-9446-4

[14] Quinlivan, P.A., Li, L. and Knappe, D.R.U. (2005) Effects of Activated Carbon Characteristics on the Simultaneous Adsorption of Aqueous Organic Micropollutants and Natural Organic Matter. Water Research, 39, 1663-1673. https://doi.org/10.1016/j.watres.2005.01.029

[15] Chen, K.L., Mylon, S.E. and Elimelech, M. (2006) Aggregation Kinetics of Alginate-Coated Hematite Nanoparticles in Monovalent and Divalent Electrolytes. Environmental Science \& Technology, 40, 1516-1523. 
https://doi.org/10.1021/es0518068

[16] Baalousha, M., Manciulea, A., Cumberland, S., Kendall, K. and Lead, J.R. (2008) Aggregation and Surface Properties of Iron Oxide Nanoparticles: Influence of $\mathrm{pH}$ and Natural Organic Matter. Environmental Toxicology and Chemistry, 27, 1875-1882. https://doi.org/10.1897/07-559.1

[17] Hyung, H., Fortner, J.D., Hughes, J.B. and Kim, J.-H. (2006) Natural Organic Matter Stabilizes Carbon Nanotubes in the Aqueous Phase. Environmental Science \& Technology, 41, 179-184. https://doi.org/10.1021/es061817g

[18] Zhang, Y., Chen, Y., Westerhoff, P. and Crittenden, J. (2009) Impact of Natural Organic Matter and Divalent Cations on the Stability of Aqueous Nanoparticles. Water Research, 43, 4249-4257. https://doi.org/10.1016/j.watres.2009.06.005

[19] Chen, K.L. and Elimelech, M. (2007) Influence of Humic Acid on the Aggregation Kinetics of Fullerene (C60) Nanoparticles in Monovalent and Divalent Electrolyte Solutions. Journal of Colloid and Interface Science, 309, 126-134. https://doi.org/10.1016/j.jcis.2007.01.074

[20] Kilduff, J.E., Karanfil, T. and Weber Jr., W.J. (1998) Competitive Effects of Nondisplaceable Organic Compounds on Trichloroethylene Uptake by Activated Carbon. I. Thermodynamic Predictions and Model Sensitivity Analyses. Journal of Colloid and Interface Science, 205, 271-279. https://doi.org/10.1006/jcis.1998.5602

[21] Newcombe, G. and Drikas, M. (1997) Adsorption of NOM onto Activated Carbon: Electrostatic and Non-Electrostatic Effects. Carbon, 35, 1239-1250.

https://doi.org/10.1016/S0008-6223(97)00078-X

[22] Mwilu, S.K., El Badawy, A.M., Bradham, K., Nelson, C., Thomas, D., Scheckel, K.G., Tolaymat, T., Ma, L. and Rogers, K.R. (2013) Changes in Silver Nanoparticles Exposed to Human Synthetic Stomach Fluid: Effects of Particle Size and Surface Chemistry. Science of the Total Environment, 447, 90-98. https://doi.org/10.1016/j.scitotenv.2012.12.036

[23] Tan, S., Erol, M., Attygalle, A., Du, H. and Sukhishvili, S. (2007) Synthesis of Positively Charged Silver Nanoparticles via Photoreduction of $\mathrm{AgNO}_{3}$ in Branched Polyethyleneimine/HEPES Solutions. Langmuir, 23, 9836-9843. https://doi.org/10.1021/la701236v

[24] Link, D.D., Walter, P.J. and Kingston, H.M. (1998) Development and Validation of the New EPA Microwave-Assisted Leach Method 3051A. Environmental Science \& Technology, 32, 3628-3632. https://doi.org/10.1021/es980559n

[25] El Badawy, A.M., Scheckel, K.G., Suidan, M. and Tolaymat, T. (2012) The Impact of Stabilization Mechanism on the Aggregation Kinetics of Silver Nanoparticles. Science of the Total Environment, 429, 325-331. https://doi.org/10.1016/j.scitotenv.2012.03.041

[26] Choudhry, G.G. (1984) Humic Substances: Structural, Photophysical, Photochemical and Free Radical Aspects and Interactions with Environmental Chemicals. Gordon and Breach Publishing Group, New York.

[27] Kilduff, J.E., Karanfil, T., Chin, Y.-P. and Weber, W.J. (1996) Adsorption of Natural Organic Polyelectrolytes by Activated Carbon: A Size-Exclusion Chromatography Study. Environmental Science \& Technology, 30, 1336-1343.

https://doi.org/10.1021/es950547r

[28] Crittenden, J.C., Trussell, R.R., Hand, D.W., Howe, K.J. and Tchobanoglous, G. (2012) Coagulation and Flocculation, MWH's Water Treatment: Principles and Design. 3rd Edition, John Wiley \& Sons, Inc., Hoboken, 541-639.

[29] Bolto, B.A. (1995) Soluble Polymers in Water Purification. Progress in Polymer 
Science, 20, 987-1041. https://doi.org/10.1016/0079-6700(95)00010-D

[30] Jaradat, A.Q., Grimberg, S.J. and Holsen, T.M. (2009) Colloid Transport through Natural Filter Media. Journal of Environmental Engineering, 135, 544-550.

https://doi.org/10.1061/(ASCE)0733-9372(2009)135:7(544) 